\section{Depression and anxiety in} sterilised women in Iran

Sterilisation is an effective and convenient means of contraception and has become increasingly popular as a birth control technique throughout the world during the past 40 years. However some women who choose sterilisation may suffer a neurotic syndrome, which is manifested in the form of pain, depression and loss of libido. 1

We undertook a study designed to investigate depression, anxiety and post-operation regret rate in sterilised women referred to health centres in Tabriz, Iran in 2006. The study design was descriptive-analytical. The study participants comprised 300 women in the age range 25-45 years, of whom 150 women were sterilised between 1 and 10 years ago and 150 were a control group of non-sterilised women who used condoms, withdrawal or safe period methods for contraception. The control group was selected by a cluster random sampling method. Fifteen health centres were selected as a cluster from 96 health centres located in Tabriz. Ten women were selected randomly from each health centre using health documents. Women were eligible for inclusion in the study if they were aged between 25 and 45 years at the time of sampling, and if they had no history of psychological disorders and no recent sorrowful events. There were no differences between the two groups as regards the number of children, income or demographic characteristics

The women were contacted by telephone at their last known address and were asked to complete questionnaires. Data collection was done using Zung's self-rating depression and anxiety scale in addition to questions about post-sterilisation regret. Data were collected from the subjects anonymously and analysed using SPSS (v. 11.5) statistics software. Analysis employed $t$-test, Chi-square test and descriptive statistics

The comparison of the means for depression in the two groups was not significantly different $(p=0.96)$, however the mean of anxiety in the case group was remarkably greater than the control group $(p=0.03)$. Insufficient poststerilisation rest was a significant risk factor for depression and anxiety $(p=0.008$ and $p=0.02$. respectively). Requesting information about reversal after tubal sterilisation was $2.7 \%$ and the post-sterilisation regret rate was $6 \%$, which was significantly related to women's conflict with their husbands about the decision-making process prior to sterilisation $(p<0.001)$

The study findings as regards psychological disorders of sterilisation suggested that women undergoing sterilisation should ensure that they have a good rest after their operation in order to reduce the extent of psychological disorders. Unlike studies undertaken in other countries, ${ }^{2-4}$ women's age, parity, marriage duration and the timing of sterilisation was unrelated to the women's regret in our study. The earlier the sterilisation is carried out, the longer the woman's remaining period of fertile life and the greater the chances of changes in her marital status and/or the loss of a child, both circumstances that may lead to a change in the desired family size and expression of regret. In our study, probably one of the reasons why women's regret did not appear to be significantly related to young age of sterilisation was the infrequency of divorce or remarriage in our study population. Consistent with our study, Jamieson et al. reported that women who had substantial conflict with their husbands or partners prior to sterilisation were more than three times as likely to regret their decision and more than five times more likely to request a reversal than women who did not report such conflict. ${ }^{5}$

In our study, pre-sterilisation counselling was reported by $29.3 \%$ of subjects. With respect to personality and adaptability differences in facing the changes, pre-sterilisation counselling and post-sterilisation follow-up systems have an important role to play in women's psychological and psychosexual health promotion.

Noorizadeh Rogayeh, MSc

Midwifery Faculty, Marand University, Marand, Iran.E-mail:rahaparva@yahoo.com

Ivanbagha Reyhaneh, MSc

Nursing and Midwifery Faculty, Tabriz

University, Tabriz, Iran

Ranjbar Koochaksaraei Fatemeh, MD Psychiatry Department, Tabriz University of Medical Science, Tabriz, Iran

Pezeshki Mohammad Zakaria, MD

Social Medicine Department, Tabriz University of Medical Science, Tabriz, Iran

Bakhtari Aghdam Fateme, MS

Health and Nutrition Faculty, Tabriz University, Tabriz, Iran

\section{References}

Kaplan HI, Sadock BJ. Synopsis of Psychiatry: Behavioral Sciences, Clinical Psychiatry (8th edn) Publishers, 2000:55.

2 Hillis SD Marchbanks PA, Tylor LR, Peterson HB. Poststerilization regret. Obstet Gynecol 1999; 93: 889-895.

3 Schmidt JE, Hillis SD, Marchbanks PA, Jeng G, Peterson HB. Requesting information about and obtaining reversal after tubal sterilization. Fertil Steri

4 2000; 74: 892-898. Chuong CJ. Sequelae of postpartum sterilization. Arch

5 Jamieson DJ, Kaufman SC, Costello C, Hillis SD, Marchbanks PA, Peterson HB. A comparison of sterilization Obstet Gynecol 2002; 99. 1073-1079.

\section{Difficult insertion of IUS}

I would like to present a case of difficult insertion of an intrauterine system (IUS) due to the failure of the device to fully extrude from the applicator despite correct deployment.

The patient, a 34-year-old woman, gravida 3 para 0 , wished to have an IUS inserted following a medical termination of pregnancy. The termination had been quite an eventful procedure as the patient had profuse bleeding requiring dilatation and curettage and a blood transfusion. When she presented for the IUS fitting the bleeding had completely stopped. The IUS was inserted very easily as per the standard technique but on retrieving the inserter the device was still attached after what appeared to be a correct deployment. A second attempt with the same device yielded an identical result and it was not until a new device was used that the procedure could be completed successfully. Fearing operator failure, it was of some consolation to note that even when held in the hand, the device (which had an unusually large tail) did not leave the inserter after full deployment (Figure 1)

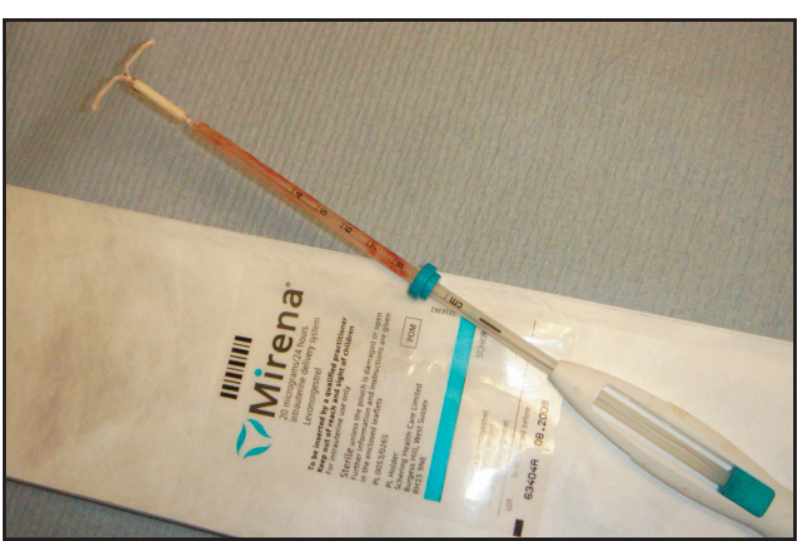

Figure 1 Photograph showing intrauterine system device still attached to inserte following unsuccessful deployment
Failure of intrauterine (IUD) or IUS deployment is likely to be an unreported event since the operator may blame themselves for not having (perhaps inadvertently) correctly deployed the device. However, it is extremely important to inspect all devices that fail in order to rule out manufacturing defects. The relative patency of our patient's cervical canal following the recent termination might have caused the faulty device to remain trapped in the inserter despite full and correct deployment. Conversely, a similarly defective device fitted in a woman with a tighter cervical os might have resulted in the device being released in the uterus but in an abnormally low position after having been dragged by the introducer on its withdrawal. In such a situation the operator would be totally unaware of the device malfunction, and the abnormally low positioning could lead to device expulsion.

The present case occurred with an IUS but it is not unreasonable to imagine that a similar mechanism could apply to different IUDs such as the TT380 Slimline ${ }^{\circledR}{ }_{1,2}$ It is thus important to collect for inspection any devices that fail to deploy correctly since this might shed some light on the reason(s) for expulsion and might perhaps lead to better quality control procedures for the device itself.

Paola Albertazzi, MD, FRCOG,

Staff Grade, Abacus, Contraception and Reproductive Health Services, Liverpool, UK.

E-mail: albertazzi@doctors.org.uk

\section{References}

Hawkins F, Callander N. Increase in IUD expulsions Letter]. J Fam Plann Reprod Health Care 2006; 32

Yadava RP. Increase in IUD expulsions [Letter]. J Fam Plann Reprod Health Care 2007; 33: 66-67.

\section{Reasons for IUD/IUS removal}

Intrauterine devices (IUDs) and the intrauterine system (IUS) are more cost effective than oral contraception. 1 Evidence from our clinics suggests that devices were being removed earlier than recommended. We therefore reviewed client contacts during 2005 in two clinics to inquire about the reasons for device removal. Table 1 shows the duration of use of IUDs at clinic attendance. The lower section of the table shows the duration of use at removal.

Of 40 devices removed, nine $(22.5 \%)$ were 'time expired' (i.e. the device was beyond its recommended duration of use). Seven $(17.5 \%)$ were removed due to bleeding problems, six $(15 \%)$ were extruded and five $(12.5 \%)$ were removed to facilitate pregnancy.

Almost half $(45 \%)$ the removals were because the devices had served their purpose. These were 'time expired' (i.e. partner had vasectomy, menopause, etc.). The remaining 55\% of devices were removed for complications or other reasons. The commonest reason for removals was bleeding (17.5\% of clients). 
Letters to the editor

\begin{tabular}{|c|c|c|c|c|}
\hline \multirow[t]{2}{*}{ Parameter } & \multicolumn{4}{|l|}{ IUD/IUS } \\
\hline & $\begin{array}{l}\text { TSafe } \\
380^{\circledR}\end{array}$ & Mirena ${ }^{\circledR}$ & NovaT® & Multiload ${ }^{\circledR}$ \\
\hline $\begin{array}{l}\text { Number } \\
\text { seen (\%) }\end{array}$ & $88(49.7)$ & $65(37.1)$ & $11(6.3)$ & $4(2.8)$ \\
\hline $\begin{array}{l}\text { Duration } \\
\text { of use }\end{array}$ & $0.5-108$ & $1-84$ & 5-132 & $0.75-26$ \\
\hline $\begin{array}{c}\text { Average } \\
\text { usage }\end{array}$ & 14.56 & 21.60 & 58.64 & 14.9 \\
\hline $\begin{array}{l}\text { Number } \\
\text { removed }\end{array}$ & 16 & 16 & 6 & 2 \\
\hline $\begin{array}{l}\text { Duration } \\
\text { of use at } \\
\text { removal }\end{array}$ & $0.5-54$ & $18-84$ & $36-132$ & $0.75-26$ \\
\hline $\begin{array}{l}\text { Average } \\
\text { usage at } \\
\text { removal }\end{array}$ & 14.4 & 44.68 & 74.16 & 13.37 \\
\hline
\end{tabular}

Table 2 shows the year of removal. Eleven $(27.5 \%)$ were removed in the first year of use, of which nine were TSafe $380^{\circledR}$ IUDs. Three of these had extruded and four were removed for bleeding. Eight $(20 \%)$ were removed in the second year, of which three TSafe 380 IUDs were removed to facilitate pregnancy. More than $50 \%$ of the IUS removed were after 5 years. There were no IUS/IUD-related pregnancies.

Table 2 Removal of intrauterine device/intrauterine system (IUD/IUS) (in year)

IUD/IUS Yea

\begin{tabular}{lllllllll} 
Year \\
\hline Y1 & Y2 & Y3 & Y4 & Y5 & Y6 & Y7 & Y8 & $>$ Y9
\end{tabular}

\begin{tabular}{llllllllll}
\hline TSafe $380^{\circledR}$ & 9 & 4 & 0 & 1 & 2 & 0 & 0 & 0 & 0 \\
Mirena $^{\circledR}$ & 1 & 4 & 1 & 1 & 8 & 0 & 1 & 0 & 0 \\
Multiload $^{\circledR}$ & 1 & 0 & 1 & 0 & 0 & 0 & 0 & 0 & 0 \\
NovaT $^{\circledR}$ & 0 & 0 & 1 & 1 & 1 & 0 & 1 & 1 & 1
\end{tabular}

In the series from the Family Planning and Reproductive Health Research Network, 238 clients had their IUS removed before 5 years for bleeding, medical and other reasons. In our series of IUS there were no removals for bleeding; the most common reason for removal being that the device had reached its recommended duration of use or contraception was no longer required.

Only $42 \%$ of all device removals were for problems related to the device itself. Most removals in the first year were of TSafe 380 IUDs. Sivin et al. ${ }^{3}$ showed the CuT380A device to have a removal rate of $23,3 / 100$ users for bleeding and an expulsion rate of 7.4/100 users at 5 years. Cox et al. ${ }^{2}$ speculated that the expulsion rate may be due to the increased copper content or the design of the device. However, could expulsion of the device also be related to the skill of the operator or poor client selection and preinsertion counselling?

We agree with Cox et al. ${ }^{2}$ that counselling before fitting the IUS is important. Likewise, careful patient selection, addressing the concerns of women and their beliefs, ${ }^{4}$ and improving communication during consultations ${ }^{5}$ helps with compliance in the use of IUDs.

Ken Menon, FFFP

Family Planning Medical Officer, Department of Sexual Health, Princess Alexandra Hospital,

Harlow,UK.E-mail:kenmenon@aol.com

Paula Moore, FFFP

Family Planning Medical Officer, Department of Sexual Health, Princess Alexandra Hospital,

Harlow, UK

\section{Beverley Penfield, MBBS}

Family Planning Medical Officer, Department of Sexual Health, Princess Alexandra Hospital, Harlow, UK

References
1 National Institute for Medicine and Clinical Excellence
(NICE). Long-acting Reversible Contraception
(Clinical Guidance CG30). October 2005.
http://guidance.nice.org.uk/CG30/niceguidance/pdf/En glish [Accessed 31 May 2007].

performance of the evonorgestrel intrauterine system in routine use by Re Health Care 2002; 28: 73-77.

3 Sivin I, el Mahgoub S, McCarthy T, Mishell DR Jr, Shoupe D, Alvarez F, et al. Long-term contraception with the levonorgestrel $20 \mathrm{mcg} / \mathrm{day}(\mathrm{LNg}-20)$ and Copper T380Ag intrauterine devices: a five-year randomised study. Contraception 1990; 42: 361-378. Asker C, Stokes-Lampard H, Beavan J, Wilson S. What is it about intrauterine devices that women find unacceptable? Factors that make women non-users: a 2006; 32: 89-94.

Van Lunsen RHW, Arnolds HT, VanMaris M. Choices and changes in contraceptive behaviour: the role information services. Patient Educ Couns 1994; 23. $197-202$.

\section{Training GPs to fit IUDs/IUS}

I was delighted to read the article on training general practitioners (GPs) to fit intrauterine devices/intrauterine systems (IUDs/IUSs) by Deborah J Lee in the July 2007 issue of the Journal. ${ }^{1}$ Dr Lee has been very proactive in developing alternatives to the traditional format for this specialised training. Having heard about her work I too have been developing a 'peripatetic' system for training clinicians, based mainly on Dr Lee's ideas. There are exciting times ahead; it is possible that practice-based commissioning will lead to a renaissance in the provision of services in the community by primary care. I have some comments:

- I have been training both doctors and nurses - particularly with Implanon ${ }^{\circledR}$ insertion and removal. Long-acting reversible contraception (LARC) provision by suitably trained nurses should be available for all women.

- There is a cohort of older GPs who have great skill and many years experience in IUD fitting who do not have any certificates or Letters of Competence (LoC). The National Enhanced Service Contract for primary care accepts their experience under 'Grandfather' rules. I have worked with Dr Mohammed Edris to develop a system of revalidation, which involves visiting the practice and observing the clinician fit at least three devices. This visit is also used as an updating and teaching session, reviewing issues such as sterilisation of equipment and current issues. My visits have been welcomed by my GP colleagues, who often work in isolated settings. The learning is mutual! I suggest that PCTs should consider incorporating some sort of a system for all providers with whom they place contracts for IUS/IUD/Implanon services.

- By training practitioners who are in established practice, I know that they will develop their services because they are responding to the needs of their locality. This is different to doctors in training completing another LoC because it will look good on their $\mathrm{CV}$.

- I also do a regular session in a community family planning clinic, and find that the pressure on appointments for LARC makes unhurried training difficult. There is increasing demand for these services when as we know there is little financial investment in community sexual health services at present.

- My colleagues in training have been supported by drug company financial support. Of course Organon has a motive to ensure that practitioners who fit and remove its implants are suitably trained, as this should reduce litigation. I see this as mutually beneficial. Primary Care Trusts (PCTs) have become very wary of involving drug companies in any form of sponsorship. There is no money specifically available for training in general practice as this is included in the 'Global Sum'. I am concerned that nurses in particular could lose the opportunity to train, as their GP employers may not see cost benefits. I now simply charge clinicians per IUD fitted this sum is slightly lower than the amount the PCT pays per fit. By training and accrediting, the practice is greatly enhancing its earning potential. I only train to the Faculty LoC standard and encourage revalidation

- My only concern is the issue of indemnity, which was not discussed by Dr Lee. As a visiting clinician undertaking a procedure on a patient registered with another doctor, I assume my liability follows me wherever I go, but my insurance company may need to consider any new risks.

- The National Institute for Health and Clinical Excellence (NICE) guidelines on menorrhagia suggest that women should be offered the IUS. ${ }^{2}$ This will not be a contraceptive service. Along with the LARC guidelines, I conclude there will be many women seeking IUS/IUDs/implants. The vision of a locally accessible service provided by well-trained clinicians will need lots more training in a variety of settings. There are opportunities for trainers to set up 'provider' services that will train and accredit, and which could be profitable.

Dee McCormack, MRCGP, FFFP

St Mary's Surgery, Ely, UK.

E-mail:dee.mccormack@nhs.net

References

Lee DJ. Training to fit intrauterine devices/intrauterine systems for general practitioners: is there an alternative method of service delivery? J Fam Plann Reprod Health Care 2007; 33: 205-207.

2 National Institute for Health and Clinical Excellence (NICE). Heavy Menstrual Bleeding (Clinical Guidance CG44). January 2007. http://guidance.nice.org.uk/ CG44/niceguidance/pdf/English [Accessed 14 August 2007].

\section{Training for the LoC IUT}

Is it time to alter the criteria for this qualification?

At the moment the training requirement for the Faculty of Family Planning and Reproductive Health Care Letter of Competence in Intrauterine Techniques (LoC IUT) is that the trainee should fit at least two different currently available devices. I have recently had one of my trainees refused her certification because she had only fitted Mirena ${ }^{\circledR}$ intrauterine systems (IUS) as there were no patients who wished to have a copper intrauterine device (IUD)

I think that the criteria need to be changed. There is now very little demand for copper IUDs in general practice. When patients are given the choice between a device which is not $100 \%$ effective and is likely to make their periods heavier, more prolonged and more painful, and one which is much more effective and will make their periods lighter and less painful, it is not surprising that they will mainly choose the Mirena. I was at a lecture last month given by a well-respected family planning instructing doctor. He was saying that copper IUDs were yesterday's technology and that we should be fitting Mirenas in everyone. [I was defending the copper IUD!] In my own general practice in the past year I have fitted 55 IUDs and only three of them were copper IUDs. Even in my family planning clinic, only 18/60 were copper IUDs.

The Faculty has to recognise the reality of the situation. Most general practitioners (GPs) will only fit Mirenas. If we refuse to accredit individuals unless they have done a copper IUD insertion then how are they going to obtain accreditation? Will we have to force patients to have copper IUDs fitted against their will? It is increasingly difficult for trainees to obtain their IUD training experience as there are fewer trainers able to do it and reduced clinics in which to be trained. There is going to be 